\title{
Health department selectively using NGO input - claim
}

Willing healthcare worker feedback to the unique Stop-Stock-Outs Coalition (SSC) stands to improve the quality and length of patients' lives - but for thousands, corrective action will take too long if government continues to ignore civil society input.

That's the message from SSC co-ordinator Sue Tafeni in response to last month's findings by a National Department of Health $(\mathrm{NDoH})$ task team after it reviewed reports on availability of medicines nationally. Consisting of local and international experts (but without any civil society coalition partners), the government task team studied reports from the Public Service Commission, the NDoH pharmaceutical team and the SSP. Tafeni described the recommendations as 'news to us', saying that the SSP was excluded from a subsequent stakeholder meeting held to discuss proposed interventions. The SSP consists of Médecins Sans Frontières, the Southern African HIV Clinicians Society, Section 27, the Rural Health Advocacy Project, the Rural Doctors Association of South Africa and the Treatment Action Campaign (TAC), all of whom have historically been well ahead of government in initiating lifesaving public sector drug access and appropriate treatment.

While welcoming the belated initiative and finance minister Pravin Gordhan's allocation of ZAR300 million for developing a national electronic medicine stock management system, Tafeni said there were huge logistic challenges. 'It will take a lot of work and time. In the meantime they must put emergency distribution and reporting systems in place - and sort out drug depot issues in the provinces.'

The electronic medicine stock management system is being piloted in two provinces. Tafeni finds it 'ironical' that the SSP, upon whose report many recommendations are based, is being 'left out in the cold', with attempts to engage with $\mathrm{NDoH}$ drug and policy chiefs allegedly proving futile. The SSP, with keen response from healthcare workers, called $79 \%$ of all primary healthcare facilities nationwide between July and October last year to find that $64 \%$ had experienced stockouts within the past 3 months and $44 \%$ were experiencing stock-outs on the day of their call. It found stock-outs of nine essential medicines, with more than half of all drug orders unplaced, insufficient or late.
Marcus Lowe, Head of Policy for the TAC, said that while they acknowledged that the government was taking steps to address stock-outs, it was not yet clear what the impact would be on patients and clinicians. 'There's a lack of transparency around exactly what they are doing and how they are measuring the impact of what they are doing. We think it's unacceptable that we've been excluded from the current process to deal with stock-outs. Civic society organisations have a huge stake in how government responds to medicines stockouts. We've clearly done substantial work on this, and to be excluded is unacceptable. We suspect that things like medicines stock-outs are symptomatic of wider dysfunction in the healthcare system. In some cases it's lack of management capacity and in some provinces it's lack of political will. In others it's just down to the politicisation of the healthcare system.'

\section{Chris Bateman}

chrisb@hmpg.co.za

S Afr Med J 2016;106(5):434.

DOI:10.7196/SAMJ.2016.v106i5.10911 